\title{
Laryngoscope Bulb - An Unusual Foreign Body in Nasopharynx
}

\author{
Poonam Marwah $\cdot$ Adhi Arya $\cdot$ Vidushi Mahajan
}

Received: 26 December 2013 / Accepted: 21 April 2014 /Published online: 9 May 2014

(C) Dr. K C Chaudhuri Foundation 2014

To the Editor: We report a case of a four-year-old boy admitted in pediatric emergency with the diagnosis of tubercular meningitis with raised intracranial tension. He required intubation for low Glasgow coma scale (E2M2V2). During endotracheal intubation, the light source of laryngoscope became nonfunctional. On inspection, the laryngoscope bulb was found to be dislodged. Child was intubated immediately with another laryngoscope. The position of bulb was found to be in nasopharynx on lateral X-ray neck (Fig. 1a). However, on direct laryngoscopy, the bulb could not be located by ENT surgeons. A repeat X-ray showed displacement of the bulb into stomach
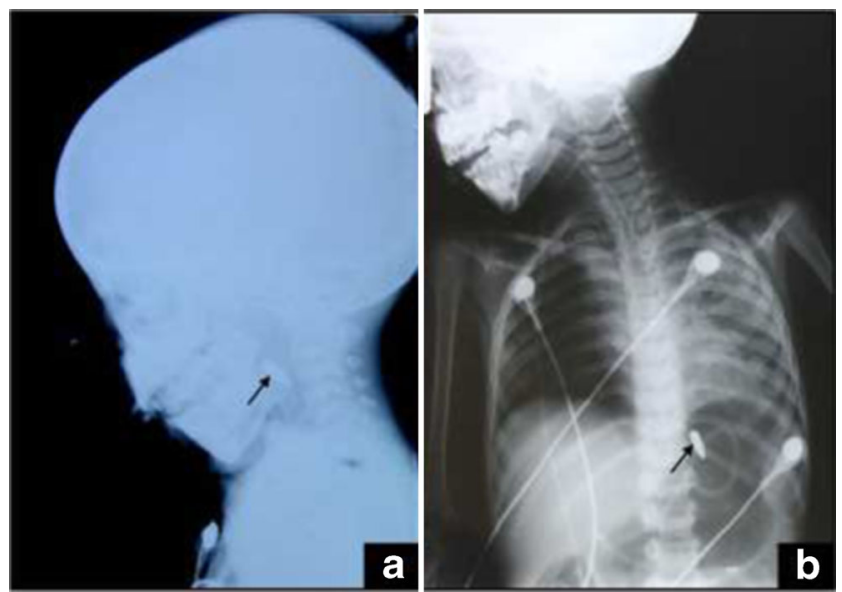

Fig. 1 a) Lateral $X$-ray neck showing laryngoscope light bulb in the nasopharynx (black arrow). b) X-ray chest and abdomen showing bulb in the stomach
(Fig. 1b). Gastroenterology opined for a conservative approach. Repeat X-ray after three days depicted displacement of bulb in ileocecal region. Unfortunately, the child expired $5 \mathrm{~d}$ later due to primary disease.

This case highlights the importance of proper checking of instruments before any procedure and, emphasises the need of rapid sequence intubation and proper sedation while performing elective endotracheal intubation [1]. Use of laryngoscope with fibreoptic illumination is another option to completely circumvent this complication [2]. However, it is costly and therefore, not recommended in routine practice. The case also alerts us on prompt reporting and management of this rare but potentially dangerous situation, if such an incident happens.

Conflict of Interest None.

Source of Funding None.

\section{References}

1. American Heart Association in collaboration with International Liaison Committee on Resuscitation. Guidelines 2000 for cardiopulmonary resuscitation and emergency cardiovascular care: international consensus on science, part 10: pediatric advanced life support. Circulation. 2000;102:I-291-342. doi:10.1161/01.CIR.102.suppl_1.I291.

2. Ince Z, Tuğcu D, Coban A. An unusual complication of endotracheal intubation: ingestion of a laryngoscope bulb. Pediatr Emerg Care. $1998 ; 14: 275-6$.
P. Marwah $\cdot$ A. Arya $\cdot$ V. Mahajan $(\bowtie)$

Department of Pediatrics, Government Medical College and

Hospital, Sector 32, Chandigarh 160030, India

e-mail: vidushimahajan2003@yahoo.co.in 